\title{
Anticipations of Monetary Policy in Financial Markets
}

\author{
Joe Lange, Brian Sack, and William Whitesell *
}

April 10, 2001

* Staff of the Board of Governors of the Federal Reserve System. We thank participants of the Monetary Affairs lunch workshop at the Federal Reserve Board for their comments. The views expressed are those of the authors and not necessarily those of the Board of Governors of the Federal Reserve System or other members of its staff. 


\title{
Anticipations of Monetary Policy in Financial Markets
}

\begin{abstract}
In recent years, financial markets appear better able to anticipate FOMC policy changes. Beginning in the late 1980s and early 1990s, longer-term interest rates and futures rates have tended to incorporate movements in the federal funds rate several months in advance, in contrast to the largely contemporaneous response typically observed before that time. After identifying these emerging trends, the paper parses the enhanced predictability into a component that can be attributed to the autoregressive behavior of the funds rate and a non-autoregressive component. The paper considers institutional developments in FOMC policy making that may have contributed to each of these components, including gradualism in adjusting the federal funds rate target and transparency regarding the setting of the target and future policy intentions.
\end{abstract}




\section{Introduction}

Through adjusting the supply of reserves, a central bank can effectively control a single asset price--the short-term interest rate. In forward-looking financial markets, however, expectations regarding the future path of short-term rates can importantly influence longer-term interest rates and stock prices, which have a considerable effect on private spending decisions. The effectiveness of monetary policy therefore depends in part on the speed and extent of the transmission of policy decisions and intentions to other asset prices. Indeed, Woodford (1999) shows that the forward-looking nature of financial markets can have important implications for determining the optimal setting of monetary policy.

The degree to which future monetary policy actions are anticipated and built into broader financial market prices has been widely studied. One of the important contributions to this literature is Mankiw and Miron (1986), who found that the yield curve has had little predictive power for future changes in short-term rates after the inception of the Federal Reserve in 1914. They argue that this result arises because the central bank tends to smooth interest rates, inducing random walk behavior that makes future rate changes largely unpredictable. The lack of predictability has been supported by numerous studies, including Shiller, Campbell, and Schoenholtz (1983) and Campbell and Shiller (1991). However, other researchers, including Fama (1984), Mishkin (1988), Hardouvelis (1988), and Longstaff (2000) have found that the yield curve does contain some information regarding future interest rate changes over particular horizons.

The variation in the findings of these papers partly reflects differences in their empirical approaches, specifications, and data. Nevertheless, a general conclusion seems to have emerged from this literature, as articulated by Cook and Hahn (1990) and Rudebusch (1995): The very short end of the yield curve displays some ability to predict changes in short-term interest rates, but this predictive power fades fairly quickly as the horizons lengthens. ${ }^{1}$ Rudebusch (1995), for example, finds that the yield curve has no information for short-rate changes beyond a month, after which the random walk behavior noted by Mankiw and Miron takes effect. However, disagreements remain 
regarding the extent to which interest rates have predictive content, and the horizon over which that predictive power exists.

We consider further the degree to which financial markets anticipate future changes in short-term interest rates, focusing on the years subsequent to the shift in the Federal Reserve's operating regime from nonborrowed to borrowed reserve targeting in the early 1980s. ${ }^{2}$ Our results indicate that an important shift occurred in the late 1980s and early 1990s in the ability of financial markets to anticipate monetary policy actions. Through most of the 1980s, market prices had predictive power for policy actions only about a month ahead, and responded substantially to contemporaneous movements in the federal funds rate. More recently, however, market yields have become much better predictors of monetary policy moves several months in advance, while the response to contemporaneous policy moves has diminished.

We review a number of hypotheses that could account for such results, including changes in market efficiency, in the nature of the shocks hitting the economy, and in the behavior of the Federal Open Market Committee (FOMC). While we cannot separate the impact of all the possible explanations, we can parse the enhanced predictability into a component associated with the autoregressive properties of the funds rate and a component associated with other factors. Regarding the first of these, it appears that the serial correlation in first differences of the federal funds rate has increased of late, likely contributing to the improved predictability of policy changes. This shift could reflect changes in the nature of the shocks to which the FOMC has responded or greater gradualism in the strategy of implementation of policy by the FOMC.

But the dynamics of the funds rate account for only part of the improved ability of financial markets to anticipate monetary policy. A considerable portion of the improvement instead appears to reflect other factors. Among those potential factors, several institutional changes have made monetary policy more transparent, including the eventual shift away from the borrowed reserve operating regime and toward strict federal funds targeting, as well as the Federal Reserve's provision of more explicit information

\footnotetext{
${ }^{1}$ Longer-term yields also seem to have some information regarding future short-rate movements, which may be associated with mean reversion, as found by Fama and Bliss (1987).

2 Some studies, including Simon (1990), have found differences in behavior after the shift in the Federal Reserve's operating regime from nonborrowed to borrowed reserve targeting in October 1982.
} 
regarding policy targets and their rationales in recent years. The increased transparency of policy formulation may have contributed to the market's improved ability to anticipate monetary policy actions.

In section 2 of the paper, we present evidence that the ability of financial markets to anticipate FOMC policy changes has improved over the period 1983 to 2000. Section 3 reviews a range of hypotheses that could possibly explain these results. Section 4 then analyzes the degree to which the greater predictability of FOMC actions may have arisen from changes in the dynamic properties of the federal funds rate. Section 5 examines empirical evidence that could shed light on whether other factors, such as increased transparency, may also have been at work in improving the predictability of FOMC policy choices. Section 6 concludes.

\section{Financial Markets and Monetary Policy}

In investigating the response of financial markets to monetary policy changes, we first focus on the behavior of Treasury and private market interest rates. The simple cross-correlations shown in Figure 1 provide a first glimpse of the dynamic relationship between market rates and the federal funds rate. The figure shows the correlation of changes in the monthly-average federal funds rate with changes in yields on six-month Treasury bills, two-and ten-year Treasury notes, and Baa-rated corporate bonds. The correlations compare a funds rate change at time zero with changes in market rates in preceding months (negative numbers along the horizontal axis) and subsequent months (positive numbers). Three subsamples are considered, each with at least five years of data. (The specific dates dividing the subsamples are discussed later in the paper.) Between 1983 to 1989 , market rates tended to move more or less contemporaneously with changes in the funds rate. Indeed, the correlation of contemporaneous changes approaches 0.75 for the six-month Treasury bill, and remains above 0.5 even for longterm yields. The correlations remain high for the movement of market rates in the month following a change in the funds rate. Moreover, anticipatory behavior was fairly limited over that sample. Changes in the funds rate are positively correlated with changes in market rates one month ahead, but the correlations fall off quickly for changes in market rates further in advance. 
The pattern of correlations since February 1994, however, has been quite different from the earlier period. Changes in the funds rate have been substantially less correlated with either contemporaneous or subsequent movements in market rates, and more highly correlated with changes in market rates two and three months beforehand. The shift in behavior apparently took place over time between the late 1980s and early 1990s, as shown by the partial shift in the correlations in the intermediate sample.

These results are explored further with a regression approach that is similar to a Granger causality test. In particular, changes in the federal funds rate are regressed on current and lagged changes in various market yields, as follows:

$$
\Delta f f_{t}=\sum_{i=0}^{N} \alpha_{i} \cdot \Delta i_{t-i}+\varepsilon_{t}
$$

where $f f_{t}$ is the effective federal funds rate, $i_{t}$ is the market interest rate, $\Delta x$ represents the monthly change in $x$, and $\varepsilon$ is the error term. ${ }^{3}$ The data are monthly averages from January 1983 to October 2000. This specification is a fairly unstructured regression that is simply intended to capture the correlation between federal funds rate movements and earlier changes in market interest rates. We can investigate whether changes in the market interest rate precede future changes in the federal funds rate by testing the significance of the coefficients from equation (1). ${ }^{4}$

To do so, rolling regressions were estimated separately for each market security over five-year periods. Figure 2 shows the significance levels (p-values) from exclusion tests on particular lags of the market yields (that is, testing the hypothesis that $\alpha_{i}=0$ for lag $i$ ) from the regression ending on the date shown. A low p-value signals a rejection of the hypothesis that those variables can be excluded, indicating that those lags indeed help

\footnotetext{
${ }^{3}$ While simultaneity bias affects the contemporaneous term, the regressions are used only to depict changing patterns of relationships over time. Simultaneity bias on the contemporaneous coefficient may have tended to reduce its significance more when market rates responded more substantially to the contemporaneous change in the funds rate. If this effect were important, it should have made it more difficult to find the changes in p-values that we report in Figure 2.

${ }^{4}$ A Granger causality test would also include lags of the funds rate changes in the specification. We are interested in whether the market rates can predict future federal funds rate movements at all, rather than whether there is an effect independent of that captured in lagged funds rate changes. The results from
} 
predict federal funds rate changes. For the six-month and two-year Treasury yields, the contemporaneous and prior-month (that is, lags 0 and 1) changes in yields have been significant predictors of funds rate changes throughout the period, as the significance level is close to zero. In contrast, the second and third monthly lags of changes in market yields played no significant role in forecasting funds rate changes through most of the 1980s. The significance of those lags shifted remarkably in the 1990s, however. The regressions ending in 1992 and later indicate that these market yields began to adjust two and three months in advance of funds rate movements. As shown by the solid lines in the lower two panels, even the longer-term yields have evidently begun to anticipate, in a statistically significant manner, changes in the funds rate two to three months ahead of time. In addition, with expected policy changes now being built into market rates a few months beforehand, market interest rates at longer horizons evidently no longer respond significantly to imminent and contemporaneous funds rate changes.

\section{The Predictive Power of the Yield Curve}

While the above results indicate that longer-term interest rates have adjusted increasingly in advance of changes in the federal funds rate, they do not address whether market rates were moving to levels that were consistent with the future path of the federal funds rate. To look at this question, we add some additional structure to the empirical exercise.

The forward-looking nature of longer-term interest rates is perhaps most simply described by the expectations hypothesis, which states that the interest rate on a longerterm $n$-period pure discount bond $\left(i^{n}\right)$ is a simple average of future short-term (oneperiod) interest rates, plus a constant term premium. If we take the one-period interest rate to be the federal funds rate $(f f)$, the following equation results, with $E_{t}$ signifying expectations as of the end of period $t$ :

$$
i_{t}^{n}=(1 / n) \sum_{i=1}^{n} E_{t} f f_{t+i}+c .
$$

sections 4 and 5 sort out whether the predictive power of market rates stems from the significance of lagged funds rate changes or from other sources. 
In our data set, $f f_{t+i}$ is equal to the average effective federal funds rate over the month $t+i$, and $i_{t}^{n}$ is the market rate at the end of the month. Any differences in tax treatment, risk, or liquidity are assumed to be captured by the term premium $c$.

The above equation has been tested in various forms by many researchers, including Campbell and Shiller (1991) and the references they cite. Under one approach, they note that the yield spread between the longer-term rate and the short-term rate should predict future changes in the short rate. Here, we use a slight modification of their formula to reflect the timing of our data (the use of a month-average federal funds rate and a month-end market rate). In particular, equation 2 implies that the following relationship must hold:

$$
i_{t}^{n}-f f_{t}-c=\sum_{i=1}^{n}\left(\frac{n+1-i}{n} E_{t} \Delta f f_{t+i}\right) .
$$

In words, the spread between the market rate at the end of the month and the federal funds rate that prevailed on average over the month, less a term premium, should equal a weighted sum of the expected changes in the monthly federal funds rate over the maturity of the longer-term instrument.

To test this equation, one can replace the expected federal funds rate changes in the right-hand side of (3) by their actual changes to determine the yield spread that would be realized under perfect foresight. That value can then be regressed on the actual yield spread (from the left-hand side of (3)), as in the following equation:

$$
\sum_{i=1}^{n} \frac{n+1-i}{n} \Delta f f_{t+i}=\alpha+\beta \cdot\left(i_{t}^{n}-f f_{t}\right) .
$$


The error term will contain an expectation error, which will be uncorrelated with the actual yield spread under rational expectations. ${ }^{5}$ According to the expectations hypothesis, the regression coefficient $\beta$ should be unity, and long rates should embody all predictable future movements in the short rate. ${ }^{6}$ The R-squared statistic from the regression then provides a measure of the portion of the weighted average future change in the federal funds rate that is anticipated by the market interest rate, which is the primary focus of this paper.

We first estimate equation (4) for the three-month Treasury bill using monthly data over our entire sample period of January 1983 through October 2000. The results (not shown) indicate an R-squared of 19 percent, a low value that is typical for such tests. But we are more interested in determining if market expectations have improved, or whether the predictive power of this equation has increased over time. We therefore split the sample at varying break points and compute the difference in the R-squared statistic between the earlier and later period for each break date. Figure 3 plots the results. As the break date moves into the late 1980s, the improvement in R-squared increases considerably. That is, the improvement in the R-squared statistics rises above zero, reaching 37 percentage points for a break date at April 1989. After leveling out for a while, the improvement again rises substantially, reaching a peak of over 70 percentage points in early 1994.

These results indicate that the ability of three-month Treasury bills to predict federal funds rate changes increased remarkably over the sample. Moreover, the improvement appears to have come over a period of time between the late 1980s and early 1990s. To capture this pattern, we introduce break points in April 1989 and February 1994 to create three distinct subsamples. We do not suggest that these precise dates were associated with any sharp change in market behavior; rather, they allow us to divide our sample period into three relatively equal segments and also serve reasonably well in helping to characterize the differences in market behavior that have emerged gradually in recent years.

\footnotetext{
${ }^{5}$ We use equation (3) to predict changes in the federal funds rate rather than changes in very short-dated Treasury bill yields because of our focus on the ability of financial markets to anticipate monetary policy actions and because bills at maturities shorter than three months are less liquid.
} 
The top portion of Table 1 reports the results from estimating the regression over the three subsamples. In the 1980s, the regression has a poor fit, and the coefficient estimate is well below the value of unity predicted by the expectations hypothesis. However, in later intervals, the coefficient has become more significant and, in the most recent subsample, has moved much closer to one. More importantly, the fit of the equation has improved considerably. The R-squared statistic jumped from less than 10 percent in the sample before 1989 to over 70 percent in the period since 1994.

In the bottom portion of the table, the spread between the six- and three-month Treasury yields is tested for its ability to predict future changes in the federal funds rate. In particular, we write equation (4) separately for the three- and six-month Treasury bills and then take the difference of those equations. The resulting equation predicts changes in the federal funds rate over the coming six months, but with a greater weight on changes between four and six months ahead. ${ }^{7}$ No relationship between the spread and federal funds rate changes over that horizon is evident in the two earlier periods, but the recent interval shows some predictive ability, with a significant coefficient of 0.5 and an R-squared of 26 percent. Overall, the results strongly indicate that there has been a considerable improvement in recent years in the ability of Treasury bill yields to predict federal funds rate changes out to three months and, to a lesser degree, at slightly longer horizons. $^{8}$

An important consideration in interpreting these results is the potential for smallsample bias. Bekaert, Hodrick, and Marshall (1997) argue that the coefficient $\beta$ in regression (4) is biased upwards in small samples as a result of the persistence of the short-term interest rate. As a result, the R-squared statistics from the regressions would also be biased upwards. However, it turns out that the bias is rather small under the dynamic process of the short-term interest rate estimated below (section 4) for the relatively short-term maturities that we consider. Moreover, the bias does not appear to have shifted significantly over the sample, and so it does not account for the sharp rise in

\footnotetext{
${ }^{6}$ Variation over time in the term premium would tend to bias the slope coefficient towards zero, as emphasized by Mankiw and Miron (1986) and others.

${ }^{7}$ In the results using futures rates below, we will be able to completely isolate the "marginal" federal funds rate changes between four and six months ahead.

${ }^{8}$ Of course, one has to be somewhat cautious in interpreting the results, given that the subsamples are quite short, as discussed in the conclusion.
} 
the R-squared statistics in the latter subsamples--the focus of this paper. The impact of the small sample bias on the results is explored in further detail in the appendix.

\section{The Predictive Power of Futures Rates}

Over recent years, private short-term instruments and futures contracts have come to rival, and even surpass, Treasury bills in terms of liquidity. There are two sets of futures contracts that may be particularly useful for predicting federal funds rate movements: federal funds futures contracts that trade on the Chicago Board of Trade, and eurodollar futures contracts that trade on the Chicago Mercantile Exchange. We use these contracts to derive equations to predict changes in the federal funds rate that are similar to the ones based on Treasury bill yields above.

Federal funds futures contracts have a payout that is explicitly based on the average effective federal funds rate over a particular month. As a result, the following equation should hold:

$$
f u t_{t}^{f f}(t+i)-f f_{t}-c=E_{t} f f_{t+i}-f f_{t},
$$

where $f f_{t+i}$ is again the average federal funds rate in month $t+i$ and $f u t_{t}^{f f}(t+i)$ is the federal funds futures rate for the contract $i$ months ahead, taken at the end of the current month. Again, $c$ represents a term premium, which is assumed constant across time for contracts with the same maturity.

As with equation 3, we replace the right-hand side of equation (5) with the actual change in the monthly-average federal funds rate and regress it on the change predicted by the futures rates. That is, we estimate the following regression:

$$
\left(f f_{t+i}-f f_{t}\right)=\alpha+\beta \cdot\left(f u t(t+i)-f f_{t}\right),
$$

where again $\beta$ should equal unity and the R-squared statistic measures the predictability of changes in the federal funds rate over the next $i$ months. Unfortunately, federal funds futures contracts were not introduced until the late 1980s, so our data are monthly 
beginning in May 1989. Our results are thus limited to the two later subperiods identified above. Also, we restrict ourselves to predictions of up to three months ahead, as federal funds futures contracts have been less liquid beyond that horizon. The results, shown in the upper part of Table 2, again indicate a marked improvement since 1994 in the proportion of federal funds rate movements that are predicted by futures prices. As was the case for Treasury bills, the adjusted R-squared statistics have increased sharply, more than doubling for all three contracts. These futures contracts have explained around 70 to 80 percent of the variance of changes in the federal funds rate in recent years. ${ }^{9}$

Eurodollar futures are liquid at longer horizons than those on federal funds. At its expiration date, which is the middle of the last month of a quarter, the value of a eurodollar futures contract is based on the three-month Eurodollar deposit rate at that time, which is heavily influenced by the outlook for the federal funds rate over the subsequent three months. Adjusting for the horizon of the contracts, an equation similar to that for federal funds futures should hold:

$$
f u t_{t}^{e d}(t+i)-f f_{t}^{q}-c=E_{t} f f_{t+i}^{q}-f f_{t}^{q} .
$$

Here, time is measured in quarters rather than months, and ${f f_{t}}^{q}$ is the average federal funds rate over the quarter ending at time $t$, where $t$ is set to be defined as a few days before the expiration of the nearest futures contract. The futures rate is observed on the same day $t$, and $f u t_{t}^{e d}(t+i)$ is the futures rate on the $i$ th contract. The first contract $(i=1)$ is just about to expire, so that its rate will essentially equal the three-month eurodollar deposit rate, which again reflects the expected federal funds rate over the upcoming quarter. The second contract $(i=2)$ would similarly reflect the expected federal funds rate two quarters ahead, and the difference in the futures rates can be used as a predictor of the federal funds rate change from four to six months out.

The regression results, using data from 1988 through the third quarter of 2000, are shown in the lower part of Table 2. Again, a remarkable improvement in the adjusted R-

\footnotetext{
9 Although the series of policy tightenings between February 1994 and February 1995 were unusually well anticipated by the market, the overall improvement in fit in the post-1994 period is not driven solely by this short episode. Starting the latter subsample after June 1995 produces similar regression results.
} 
squared is evident since early 1994, and the regression explains more than 70 percent of the variation in federal funds rate changes over a three-month horizon. In addition, some predictive ability has even emerged for federal funds rate changes between months four to six, which was non-existent before 1994.

\section{Policy Surprises}

The results from Table 2 provide evidence that market interest rates are building in a large portion of FOMC policy actions several months in advance. As a consequence, markets should now be less surprised at the time of the announcement of a monetary policy action and therefore should react less than in the past. We test for this, measuring the surprise component of the FOMC's policy decisions by the change in the current month federal funds futures rate on the day the policy decision became known, as in Kuttner (2000). ${ }^{10}$ Because the futures contract is based on the average federal funds rate over the month, the amount by which the futures rate reacts to an unexpected policy change depends on its timing within the month. A measure of the policy surprise that accounts for this timing is: ${ }^{11}$

$$
\text { Policy Surprise }=\frac{D}{D-d} \Delta f u t^{f f}
$$

where $\Delta f u t^{f f}$ is the change in the current month federal funds futures rate on the day of the federal funds rate change became known, $d$ is the day of the month of the policy action, and $D$ is the total number of days in the month.

The average size of this statistic over different subsamples, reported in Table 3, reveals a substantial decline in the unanticipated component of policy moves over the

10 Before 1994, changes in the intended funds rate were not announced on the day of change. The market typically learned of such decisions through implicit signaling by the choice of open market operation the following day. However, even before 1994, discount rate changes were announced on the day of change, and the market could then typically interpret the implications for the funds rate that day. For these reasons, a two-day change in the current month federal funds futures rate is used to measure the surprise in the policy action before 1994 .

11 The equation is only approximately correct, because it does not account for the small change in the term premium on the day of the policy action or the amount by which the effective funds rate deviated from the target on the day of the policy action. However, these effects should be small. 
more recent period. In the period before 1994, the average size of a federal funds rate change was 27 basis points, of which 16 basis points, or 59 percent, came as a surprise to the market. Since 1994, however, while the average size of policy moves has increased to over 32 basis points, only 8 basis points of those moves, or 24 percent, has been a surprise. $^{12}$

\section{Possible Interpretations}

The results of the previous section suggest that a significant shift has occurred in the relationship between financial market prices and movements in the federal funds rate. A wide range of interpretations of these developments is possible, including hypotheses regarding changes in the efficiency of markets, in the nature of the economy, or in the behavior of the FOMC.

Some observers have argued that the deepening of futures markets in eurodollars and federal funds since the late 1980s has reduced transactions costs and facilitated arbitrage. Hatzius (1999) argued that the enhanced liquidity of futures markets has made other market interest rates more responsive to informed views on near-term expectations for monetary policy. We believe any such effect to be rather limited, however, as improved predictability of short rates has been evident also in the Treasury bill market, which has been liquid enough throughout the last two decades to provide ample opportunity for position-taking and arbitrage across markets based on policy expectations.

The market's improved predictive abilities might alternatively be related to a shift in the nature of the shocks hitting the economy. It is possible that the shocks affecting the economy over recent years have become more persistent or serially correlated. If monetary policy reacts systematically to changes in macroeconomic variables, such a shift could increase the predictability of policy changes. A number of studies have found changes in the stability of the economy in the period since 1980, but it may be premature to assess whether there have been changes in the shocks or internal dynamics of the economy as a whole since the mid-1990s.

12 While the magnitude of the surprises in policy actions has fallen in recent years, the response of market interest rates to a policy surprise of a given size appears to have remained unchanged, as explored in detail 
Another set of hypotheses would consider whether the improved anticipatory behavior of financial markets has arisen in part from changes in the policy-setting practices of the Federal Reserve or in the transparency of its intentions. Indeed, a number of institutional changes have taken place over the past two decades. One of the most obvious of those changes was the move towards a clear regime of federal funds rate targeting. Recall that from October 1979 through September 1982, the Federal Reserve had employed a nonborrowed reserve operating procedure, directing the Open Market Desk to adjust nonborrowed reserves consistent with an intended path for growth of the monetary aggregates, within a wide range of permissible federal funds rates. Through most of the rest of the 1980s, a borrowed reserve operating regime prevailed, which was intermediate between nonborrowed reserve and federal funds rate targeting. The FOMC's policy stance during this regime was expressed in terms of a target level of discount window borrowing that was associated with an expected level of money growth and the federal funds rate. However, with an unannounced operating target for borrowing, the true intentions of the FOMC were not always evident to the markets.

No clear break point exists for the shift from borrowed reserve targeting to strict federal funds rate targeting, but a few key dates in the transition can be mentioned. In the mid-1980s, when a change was thought to be detected in the relationship of discount window borrowing to the spread between the federal funds rate and the discount rate, "technical adjustments" were at times made in the range of federal funds rates associated with an unchanged borrowing assumption. Following the stock market crash in October 1987, the FOMC's directives specified that greater flexibility should be used, implying that the Desk should give priority to keeping the federal funds rate close to expectations, rather than keeping borrowing at its target level. In November 1988, in the face of another evident shift in the demand function, the FOMC made a substantial technical adjustment to the borrowing assumption itself--rather than allowing the expected federal funds rate to change. ${ }^{13}$ While the Desk had used a point value for the intended funds rate rather than a range at certain times, such as after the 1987 equity market crash, it dropped any further use of ranges after June 1989. Nevertheless, the market misinterpreted

by Bomfim and Reinhart (2000) and Kuttner (2000).

${ }^{13}$ Federal Reserve Bank of New York (1989). 
reserve adjustments made around Thanksgiving 1989 as a policy change, and the Desk thereafter began to target the federal funds rate even more closely and to signal that target more clearly to the markets. ${ }^{14}$ Thereafter, hitting the borrowing assumption no longer took precedence over targeting the federal funds rate in the implementation of policy, and the target federal funds rate was readily discernable by market participants.

The policy process has become more transparent in a number of other ways as well, which may have also contributed to an increase in the predictability of federal funds rate movements. An important step towards increased transparency took place in February 1994, when the FOMC began announcing policy changes on the day of its meetings, and included reasons for those decisions that often held hints about future policy intentions. ${ }^{15}$ In July 1995, the FOMC began including explicit references to the intended federal funds rate in the press releases following its meetings, and in August 1997, it began referring to an explicit funds rate target in its directives to the Open Market Desk. Another major step took place in May 1999, when the FOMC began releasing changes in its policy "bias" at the conclusion of its meetings. In February 2000, it switched to a statement after each meeting of its views regarding the balance of risks in the economic outlook. ${ }^{16}$ Since that time, the press release has also described the rationale for the policy decision at each meeting and the factors underlying the balance of risks. Lastly, increased transparency may also be evident in the nature of the speeches and public comments of FOMC members in recent years, which some market participants believe to be more informative about future policy moves than in the past.

Partly as a result of receiving clearer information about the actual policy setting and the factors underlying policy decisions, market participants have likely improved their understanding of the determination of monetary policy over the sample. Indeed, there has been a rapidly expanding academic literature on estimating and evaluating monetary policy rules, following the important contributions of Taylor (1993). One of

\footnotetext{
${ }^{14}$ For signaling methods used by the Open Market Desk, see Feinman (1993).

15 Bomfim and Reinhart (2000) found that the shift to policy announcements in February 1994 did not seem to increase the response of markets to a surprise in the federal funds rate of a given size. We instead focus more closely on the impact of policy announcements on the magnitude of the policy surprise and the timing of movements in market interest rates.

${ }^{16}$ At that time, the traditional language regarding asymmetry in the chances for an easing or tightening of policy was replaced with language regarding the balance of risks facing the economy, which the FOMC intended to be less closely linked to imminent policy moves.
} 
the conclusions from that literature is that U.S. monetary policy can be reasonably approximated by simple policy rules that respond systematically to macroeconomic data. That understanding may have improved the anticipatory ability of the markets. ${ }^{17}$ Moreover, many estimated policy rules find evidence of partial adjustment in the target federal funds rate, which would make federal funds rate changes even more predictable. As suggested by Woodford (1999), such a strategy may allow a central bank to reduce the volatility of short-term interest rates, while anticipatory adjustments of longer-term rates effectively stabilize the economy. In fact, because long-term rates are now adjusting farther in advance of eventual policy moves, more gradual behavior by the FOMC may have become optimal. ${ }^{18}$

We do not attempt to evaluate empirically all the differing hypotheses that might account for the observed change in anticipatory behavior. However, we take an initial step below in exploring whether insights can be gained from parsing out the predictability of the federal funds rate that is attributable to its autoregressive properties.

\section{Changes in the Federal Funds Rate Process}

The improved ability of financial markets to anticipate monetary policy over the latter part of the sample could partly reflect a shift in the dynamic behavior of the federal funds rate that has made its movements more predictable. While a number of authors have investigated the univariate properties of the federal funds rate (e.g., Rudebusch, 1995, and references therein), we focus on the period since the onset of the borrowed reserve operating regime in the early 1980s and look for changes in behavior in more recent years.

To capture the dynamics of the federal funds rate, we regress the monthly change in the federal funds rate on three of its own lags. ${ }^{19}$ As shown in the top panel of Table 4,

\footnotetext{
${ }^{17}$ Fuhrer (1996) has shown that the form of the policy rule can have important implications for the behavior of the term structure.

${ }^{18}$ Another hypothesis is that markets may appear more anticipatory because policy has become more responsive to them. It is unclear how the data could disentangle this proposition from the idea that policy makers now make greater attempts to prepare markets for future policy actions. The latter view could be interpreted as a feature of a general trend toward increased transparency in policy making.

${ }^{19}$ We are not taking a strong stand on whether the interest rate is non-stationary. Assuming stationarity by adding a lagged level of the rate as an additional regressor does not affect the results strongly. The
} 
only the first lagged dependent variable is significant when the regression is estimated over our full sample period of January 1983 to October 2000. However, an Andrews (1993) test for a structural break at an unknown date suggests that the regression is unstable across the sample. The likelihood ratios used to test for a change in estimated coefficients at each potential break month are plotted in Figure 4. These ratios reached a maximum in December 1987 and, according to the Andrews criterion, indicates a structural break at the 10 percent significance level.

Separate regressions run on either side of the break point indicate that the second and third monthly lags of the change in the federal funds rate have become significant regressors in the period since late 1987, as shown in Table 4. The autoregressive process shows a better fit in the recent period, with the adjusted R-squared rising to 32 percent from under 10 percent in the earlier sample. The results indicate that the federal funds rate has demonstrated increased inertia in its movements over the more recent period, making future changes more predictable. As shown by the solid line in Figure 5, a tightening of 25 basis points is now expected to be followed on average by an additional 50 basis points of tightening over the subsequent year. In the 1980 s, by contrast, a 25 basis point tightening was typically followed by only another 13 or so basis points of action.

The federal funds rate data used above, however, may not precisely reflect the intentions of the FOMC. The effective federal funds rate can deviate from the FOMC's intended level, although such deviations tend to be small on average over a month. Also, a monthly interval does not correspond to a natural FOMC decision-making cycle. For these reasons, we investigated the autoregressive properties of changes in the intended federal funds rate from one FOMC meeting to the next, which occur about every six weeks. ${ }^{20}$ A regression of the change in the intended rate on its own lags and the lagged level, shown in the bottom panel of Table 4, indicates that only one lagged dependent variable was significant when estimated over the entire sample. Again, however, an

coefficient on the lagged level is not significant over the entire sample, but has become significant in the most recent subsample.

${ }^{20}$ Although the FOMC did not strictly target the funds rate through most of the 1980s, as mentioned above, the Open Market Desk nevertheless associated the FOMC's choices of borrowing targets with an intended funds rate, or a narrow range for the funds rate. This range was much smaller than the range 
Andrews test reveals a significant structural break occurring in October 1989, a bit later than that found in the monthly specification. Regressions estimated over the implied subsamples show that only one lag was significant in the earlier subperiod, and that a second lag has become significant in the latter interval. Thus, the pattern is similar to the one found under monthly observations, as two FOMC cycles corresponds to roughly three months.

While changes in the federal funds rate have become somewhat more serially correlated in recent years, this does not necessarily imply an intentional strategy of the FOMC to phase in periods of tightening or easing more gradually. An alternative hypothesis, as noted above, is that the shocks hitting the economy, to which the FOMC has responded, may have themselves become more serially correlated. Whatever the interpretation, the shift toward greater serial correlation in changes in the federal funds rate should have improved the predictability of policy decisions. Of course, the above break dates for the autoregressive coefficients were identified only with hindsight, and it may have taken market participants some time to realize that the behavior of the federal funds rate had shifted. But over time, the increased predictability of future federal funds rate changes associated with the shift in its dynamic properties likely contributed to the improvement in the predictive power of market interest rates. The next section explores whether this factor accounts for all of the improvement, or whether other factors were also at work.

\section{Other Sources of Predictability}

In this section of the paper, we explore whether factors other than the dynamic properties of the federal funds rate have contributed to the improved predictive power of market interest rates. To do so, we initially return to the Campbell-Shiller-type regression from Table 1 (equation (4)), focusing on the three-month Treasury bill. One would expect the Treasury bill yield to incorporate any available information about the path of the federal funds rate, including changes in its autoregressive properties. Thus, the greater autocorrelation of federal funds rate changes in recent years could account for

mentioned in the FOMC's formal directive to the Desk. The intended funds rate series we use was reported in Rudebusch (1995). 
a portion of the improvement in its predictive power over the sample. To gauge the impact of this component, we begin by regressing the dependent variable from equation (4) on just the lags of the federal funds, shown by "Specification A" in Table $5 .{ }^{21}$ As would be expected from the results of the previous section, the dynamics of the federal funds rate have explained a larger share of the (weighted) changes in the federal funds rate in more recent samples. Indeed, the results indicate that there were even additional improvements in the period since 1994, well after the break point found in the previous section. The R-squared statistic from Specification A improves from about 10 percent in the earliest subsample to over 25 percent in the most recent subsample.

Based on this result, a portion of the improved predictive power of the Treasury bill yield can likely be attributed to the change in the dynamic properties of the federal funds rate. But it appears that other factors were even more important. "Specification B" adds to the regression the spread between the three-month Treasury bill and the federal funds rate. The interest rate spread soaks up much of the significance of the autoregressive variables, consistent with the notion that it incorporates changes in the dynamic behavior of the federal funds rate. If this were the only information that it captured, however, the adjusted R-squared statistic would not improve moving from Specification A to B. Instead, the fit of the equation improves considerably in all of the subsamples, indicating that the Treasury yield captures additional information about the future path of the federal funds rate. More importantly, while the fit improves only modestly in the earlier subsamples, it improves dramatically in the period since 1994, in which the adjusted R-squared rises from 25 percent to 74 percent. Indeed, the results show that the majority of the improvement in the R-squared from the earlier to the more recent periods can be attributed to information beyond the autoregressive behavior of the federal funds rate.

A similar exercise is employed using federal funds futures (corresponding to the upper panel of Table 2), with horizons of one-, two-, and three-months ahead. Table 6 reports the R-squared statistics from the two specifications over the different subsamples.

21 Note that market participants are unlikely to have built in the full properties of the autoregressive model we fit, given that the information was not available in real time. Therefore, our test may have a bias against finding any important predictive power in market quotes beyond that captured by lagged changes in funds rates. 
Adding futures market quotes to the regression results in a substantial improvement in the proportion of the variance of changes in the federal funds rate explained in each of the subsamples, indicating that futures rates clearly contain information beyond what is evident from the univariate properties of the federal funds rate. The improvement in fit from adding the futures quotes is striking in the more recent sample, increasing from a 17 to 24 percentage points in the earlier period to over 50 percentage points in the later interval. $^{22}$

Of course, it is difficult to estimate the exact decomposition of the improved predictive ability of market rates into autoregressive and non-autoregressive components. As noted above, it is not clear how quickly market participants would have realized these shifts in behavior, which we have identified with hindsight. Moreover, the relative importance of the two components is influenced to some extent by the assumed specification of the autoregressive process. ${ }^{23}$ Nevertheless, the results under alternative specifications also indicate that the non-autoregressive component has been an important factor in the improved predictive power of market interest rates. As discussed in the previous section, a wide range of factors could have had a hand in producing these results. One possibility is that the implicit reaction function of the FOMC may have become more apparent to markets over the latter part of the sample. In addition, the efforts by the FOMC to make its decision making and reading of the economy more transparent may have improved the market's ability to anticipate future FOMC actions.

\section{Conclusions}

This paper has found fairly striking evidence of an improved ability of financial markets to predict future changes in policy by the FOMC. The shift in behavior appeared to take place over a period ranging from the late 1980s to early 1994. We show that a portion of the improved predictability of FOMC actions can be associated with stronger

\footnotetext{
22 In an alternative approach, the residuals from the autoregressive equations were regressed on the component of the futures market predictions that were orthogonal to the autoregressive terms. Over the six regressions (one-, two-, and three-month ahead horizons for each of the two subsamples), the orthogonal component of the futures market predictions were all significant, with t-statistics ranging between 3.7 and 14.1.

${ }^{23}$ For example, the federal funds rate in the most recent sample has demonstrated increased mean reversion, which our specification does not capture. In tests that allow for this effect, the increase in the predictive power is more evenly balanced across the autoregressive and non-autoregressive components.
} 
serial correlation in changes in the federal funds rate. However, we do not attempt to distinguish whether these more pronounced autoregressive properties are attributable to a deliberate strategy of a slower phasing-in of policy adjustments or rather to changes in the underlying nature of the economy. Furthermore, the results indicate that factors other than the autoregressive properties of the federal funds rate appear to have played an important role in enhancing the predictability of FOMC actions.

Among those other factors, the Federal Reserve has implemented a number of changes that may have improved the transparency of the process of setting monetary policy. The Federal Reserve gradually shifted away from the borrowed reserve operating procedure that had been in place in the mid-1980s in favor of strict targeting of the federal funds rate. Moreover, the FOMC began announcing policy changes on the day of its meetings, and offering some explanation of those decisions, in 1994. In addition, the speeches and public comments of FOMC members may now better prepare the markets for future policy moves. While we do not investigate these factors individually, collectively they could allow market participants to anticipate future federal funds rate movements more accurately and farther in advance than before, as reflected in the behavior of market interest rates.

A caveat to the findings is that, because of our focus on the importance of recent changes, we are unavoidably left with short sample periods. We have been careful to check that our results have not been driven by small sample bias or by the influence of individual episodes. Moreover, the increase in predictability is remarkably strong and is evident in a number of different markets, giving more credence to the findings. 


\section{References}

Andrews, D., 1993, Tests for parameter instability and structural change with unknown change point, Econometrica 61 no. 4, 821-856.

Bekaert, G., R. Hodrick, and D. Marshall, 1997, On biases in tests of the expectations hypothesis of the term structure of interest rates, Journal of Financial Economics 44, 309-348.

Bomfim, A. and V. Reinhart, 2000, Making news: Financial market effects of Federal Reserve disclosure practices, Financial and Economics Discussion Series no. 14.

Campbell, J. and R. Shiller, 1991, Yield spreads and interest rate movements: A bird's eye view, Review of Economic Studies 58, 495-514.

Cook, T. and T. Hahn, 1989, The effect of changes in the federal funds rate target on market interest rates in the 1970s, Journal of Monetary Economics 24, 331-351.

Cook, T. and T. Hahn, 1990, Interest rate expectations and the slope of the money market yield curve, Economic Review (Federal Reserve Bank of Richmond), 3-26.

Fama, E.F., 1984, The information in the term structure, Journal of Financial Economics 13, 509-528.

Fama, E.F., and R.R. Bliss, 1987, The information in long-maturity forward rates, American Economic Review 77, 680-692.

Federal Reserve Bank of New York, 1989, Monetary policy and open market operations during 1988, Quarterly Review (Winter-Spring), 83-102.

Feinman, Joshua, 1993, Estimating the Open Market Desk's daily reaction function, Journal of Money, Credit, and Banking 25, 231-247.

Fuhrer, J.C., 1996, Monetary policy shifts and long-term interest rates, Quarterly Journal of Economics, November, 1183-1209.

Hardouvelis, G.A., 1988, The predictive power of the term structure during recent monetary regimes, Journal of Finance 43, 339-356.

Hatzius, J., 1999, Can the bond market do the Fed's dirty work, Goldman Sachs Global Economic Research, November 12.

Kuttner, K., 2000, Monetary Policy Surprises and Interest Rates: Evidence from the Fed Funds Futures Market, Federal Reserve Bank of New York Staff Report no. 99.

Longstaff, F.A., 2000, The term structure of very short-term rates: New evidence for 
the expectations hypothesis, Journal of Financial Economics 58, 397-415.

Mankiw, N.G. and J.A. Miron, 1986, The changing behavior of the term structure of interest rates, Quarterly Journal of Economics 101, 211-228.

Mishkin, F., 1988, The information in the term structure: Some further results, Journal of Applied Econometrics 3, 307-314.

Rudebusch, G., 1995, Federal Reserve interest rate targeting, rational expectations, and the term structure, Journal of Monetary Economics, 35, 245-274.

Shiller, R.J., J.Y. Campbell, and K.L. Schoenholtz, 1983, Forward rates and future policy: Interpreting the term structure of interest rates, Brookings Papers on Economic Activity no. 1, 173-224.

Simon, D.P., 1990, Expectations the treasury bill-federal funds rate spread over recent monetary policy regimes, Journal of Finance 45, 567-577.

Woodford, M., 1999, Optimal monetary policy inertia, Manchester School Supplement, 1-35. 


\section{Appendix}

Small-sample bias in the results. Bekaert, Hodrick, and Marshall (1997), hereafter BHM, report significant small-sample bias in several regression-based tests of the expectations hypothesis, including the Campbell-Shiller specification estimated in Table 1 and repeated here:

$$
\sum_{i=1}^{n} \frac{n+1-i}{n}\left(\Delta f f_{t+i}\right)=\alpha+\beta \cdot\left(i_{t}^{n}-f f_{t}\right)
$$

As BHM explain, the persistence of short-term rates creates an upward bias in the slope coefficient of equation (3a) in small samples. However, the size of the bias is heavily influenced by the data-generating process of the short-term interest rate. In particular, negative correlation between short rates and the yield spread tends to amplify the upward bias on the slope coefficient. BHM initially consider the case in which the short-term interest rate follows an $\mathrm{AR}(1)$ process. There is a sizable small-sample bias in that case because the correlation between the short-term interest rate and the yield spread is precisely -1 under the expectations hypothesis, as innovations to the short-term rate are expected to begin unwinding gradually but immediately. BHM also consider a more general case in which the path of the short-term interest rate is generated by a secondorder VAR that allows for heteroskedasticity. In that case, the negative correlation between the short rate and the 12-month yield spread is about -0.5 , and the small-sample coefficient bias is substantially reduced.

We consider a specification that, in terms of generality, falls between these two cases. In particular, as shown in Table 4, we find that the behavior of the month-average federal funds rate in recent years can be effectively characterized by a third-order autoregressive process in changes. We therefore investigate the biases that result when the federal funds rate is assumed to follow that process, where the parameters of the process are estimated separately for the different subsamples. As a check of the robustness of our findings, we also report results under the assumption that the federal 
funds rate follows an $\mathrm{AR}(1)$ process. While that specification can be rejected in the data, it allows us to compare results to the worst case considered by BHM.

Note that BHM also adjust for small sample biases in the estimates of the dynamic process of the short-term interest rate. In our case, the adjustment to the firstorder autoregressive process in levels would make the federal funds rate look like a random walk, which is an uninteresting case because the yield spread should then never change under the expectations hypothesis. Because the third-order differenced process that we consider implicitly nests the random walk case, we do not employ an adjusted levels process. Small-sample biases in the differenced process are very small, and thus no adjustment is needed for that specification.

Table A.1 reports average point estimates of $\beta$ with both first-order in levels and third-order in changes autoregressive generating processes for the short-term interest rate based on 1000 Monte Carlo simulations:

Table A.1

Average $\beta$ Coefficient for Equation 3a

(1000 Monte Carlo replications)

\begin{tabular}{ccc}
\hline $1983: 1$ to $1989: 3$ & \multicolumn{2}{c}{ Number of Observations } \\
$f f_{t}=.185+.978 f f_{t-1}$ & $n=75$ & $n=5000$ \\
$\Delta f f_{t}=.439 \Delta f f_{t-1}+.030 \Delta f f_{t-2}-.048 \Delta f f_{t-3}$ & 3.33 & 1.03 \\
$1989: 4$ to $1994: 1$ & 0.90 & 1.00 \\
$f f_{t}=.097+.983 f f_{t-1}$ & $n=58$ & $n=5000$ \\
$\Delta f f_{t}=.372 \Delta f f_{t-1}+\Delta .248 f f_{t-2}+.132 \Delta f f_{t-3}$ & 6.14 & 1.05 \\
$1994: 2$ to $2000: 10$ & 0.81 & 1.00 \\
$f f_{t}=.445+.924 f f_{t-1}$ & & \\
$\Delta f f_{t}=.221 \Delta f f_{t-1}+.274 \Delta f f_{t-2}+.148 \Delta f f_{t-3}$ & 1.59 & $n=5000$ \\
& & 0.86 \\
\hline
\end{tabular}

The estimates in the large sample $(n=5000)$ approximate the asymptotic value of the coefficient, which is 1.0. Under the first-order autoregressive process, the small sample bias pushes the coefficients significantly above that value in the small sample $(n=75,58$, and 81, respectively). However, the bias is much less severe under the third-order autoregressive changes process and are in fact below unity. The reason is that the 
correlation between innovations to the federal funds rate and changes in the yield spread is small and slightly positive under the more flexible dynamic process, as opposed to the strong negative correlation under the $\mathrm{AR}(1)$ process. This is consistent the finding in BHM that the $\mathrm{AR}(1)$ model overstates the bias (for shorter maturities) relative to a more general VAR specification.

The bias in the slope coefficient in small samples also affects the R-squared statistic of the regression, as seen in Table A.2. However, similar to the results for the coefficient bias reported the above table, the upward bias on the R-squared statistic is fairly small when the short-term interest rate is assumed to follow a third-order autoregressive process in changes. Moreover, even under the first-order process, the positive bias on the slope coefficient and the R-squared statistic appears to be smaller in the more recent sample--opposite the pattern of the R-squared statistic that we find. Under the third-order differenced process, the bias tends to pull down the R-squared statistic in the more recent subsamples, again pushing in the opposite direction of our findings. Based on this evidence, it appears very unlikely that the small sample bias is accounting for the improvement of the regression fit over the sample, thereby strengthening our claim that short-rates have become better predictors of longer-term rates in recent years.

Table A.2

\section{Average $\boldsymbol{R}^{2}$ Statistic for Equation 3a}

(1000 Monte Carlo replications)

\begin{tabular}{ccc}
\hline $1983: 1$ to $1989: 3$ & \multicolumn{2}{c}{ Number of Observations } \\
$f f_{t}=.185+.978 f f_{t-1}$ & $n=75$ & $n=5000$ \\
$\Delta f f_{t}=.439 \Delta f f_{t-1}+.030 \Delta f f_{t-2}-.048 \Delta f f_{t-3}$ & 0.11 & 0.03 \\
$1989: 4$ to $1994: 1$ & 0.13 & 0.14 \\
$f f_{t}=.097+.983 f f_{t-1}$ & $n=58$ & $n=5000$ \\
$\Delta f f_{t}=.372 \Delta f f_{t-1}+\Delta .248 f f_{t-2}+.132 \Delta f f_{t-3}$ & 0.14 & 0.02 \\
$1994: 2$ to $2000: 10$ & 0.23 & 0.32 \\
$f f_{t}=.445+.924 f f_{t-1}$ & & \\
$\Delta f f_{t}=.221 \Delta f f_{t-1}+.274 \Delta f f_{t-2}+.148 \Delta f f_{t-3}$ & $n=81$ & $n=5000$ \\
& 0.15 & 0.10 \\
\end{tabular}




\section{Table 1}

Predicting Federal Funds Rate Changes with Treasury Bill Yields (Campbell-Shiller Regressions)

$$
\begin{gathered}
\text { Spec. A: } \sum_{i=1}^{n} \frac{n+1-i}{n} \Delta f f_{t+i}=\alpha+\beta \cdot\left(i_{t}^{n}-f f_{t}\right) \\
\text { Spec. B: } \sum_{i=1}^{m} \frac{m+1-i}{m} \Delta f f_{t+i}-\sum_{i=1}^{n} \frac{n+1-i}{n} \Delta f f_{t+i}=\alpha+\beta \cdot\left(i_{t}^{m}-i_{t}^{n}\right)
\end{gathered}
$$

\begin{tabular}{lcccc}
\hline & $\begin{array}{c}\text { Horizon for Pred. } \\
\text { Funds Rate Change } \\
\text { (months) }\end{array}$ & $\begin{array}{c}\text { Number } \\
\text { of } \\
\text { Obs. }\end{array}$ & $\begin{array}{c}\beta \text { Coefficient } \\
\text { (t-statistic) }\end{array}$ & $\begin{array}{c}\text { Adjusted } \\
\text { R-squared }\end{array}$ \\
\hline Spread of 3-month Treasury Bill over Funds Rate (Spec. A, $n=3)$ & \\
1983:1 to 1989:3 & 3 & 75 & $0.496(2.79)$ & .092 \\
1989:4 to 1994:1 & 3 & 58 & $0.371(3.43)$ & .268 \\
1994:2 to 2000:10 & 3 & 79 & $0.679(12.44)$ & .729 \\
Spread of 6-month over 3-month Treasury Bill (Spec. B, $n=3, m=6)$ & \\
1983:1 to 1989:3 & 6 & 75 & $-0.332(-0.75)$ & .021 \\
1989:4 to 1994:1 & 6 & 58 & $0.322(0.98)$ & .003 \\
1994:2 to 2000:10 & 6 & 76 & $0.520(3.95)$ & .256 \\
\end{tabular}

Regressions predict a weighted sum of changes in the federal funds rate over the horizon indicated. This specification corresponds to Table 2 from Campbell and Shiller (1991). Data are monthly from 1983:1 to 2000:10. All standard errors are corrected for heteroskedasticity and serial correlation using the Newey-West procedure. 
Table 2

Predicting Federal Funds Rate Changes with Futures Rates

Spec. A: $\left.\left(f f_{t+i}-f f_{t}\right)=\alpha+\beta \cdot\left(f u t_{t}(t+i)-f f_{t}\right)\right)$

Spec. B: $\left(f f_{t+i}-f f_{t+i-1}\right)=\alpha+\beta \cdot\left(f u t_{t}(t+i)-f f_{t}(t+i-1)\right)$

\begin{tabular}{cccc}
\hline $\begin{array}{c}\text { Horizon for Pred. } \\
\text { Funds Rate } \\
\text { Change } \\
\text { (months) }\end{array}$ & $\begin{array}{c}\text { Number } \\
\text { of }\end{array}$ & $\begin{array}{c}\beta \text { Coefficient } \\
\text { (t-statistic) }\end{array}$ & $\begin{array}{c}\text { Adjusted } \\
\text { R-squared }\end{array}$ \\
\hline
\end{tabular}

Federal Funds Futures

$1^{\text {st }}$ contract (Spec. A, $i=1$ )

1989:5 to $1994: 1$

1994:2 to 2000:10

$2^{\text {nd }}$ contract (Spec. $A, i=2$ )

1989:5 to $1994: 1$

1994:2 to 2000:10

$3^{\text {rd }}$ contract (Spec. $A, i=3$ )

1989:5 to $1994: 1$

1994:2 to 2000:10

1

1

2

2

3

3
57

81

$0.642(4.87)$

0.909 (11.40)

.330

.701

.319

$57 \quad 0.748(3.32)$

$0.940(10.16)$

.802

\section{Eurodollar Futures}

$1^{\text {st }}$ contract (Spec. A, $\left.i=1\right)$

$\begin{array}{lllll}1988: 1 \text { to } 1993: 4 & 3 & 19 & 0.594(3.72) & .188 \\ 1994: 1 \text { to } 2000: 3 & 3 & 25 & 0.851(8.28) & .745\end{array}$

$2^{\text {nd }}$ contract (Spec. $\left.B, i=2\right)$

1988:1 to 1993:4

1994:1 to 2000:3

$4-6$
$4-6$

19

$0.240(0.69)$

$-.031$

4-6

24

0.527 (3.61)

.267

Regressions predict the change in the federal funds rate over the horizon indicated. Data for federal funds futures are monthly from 1989:5 to 2000:10. Data for eurodollar futures are quarterly from 1988:1 to 2000:3. For the $2^{\text {nd }}$ eurodollar contract, a marginal effect is estimated using the spread of the six- minus three-month contracts on the right-hand-side. All standard errors are corrected for heteroskedasticity and serial correlation using the Newey-West procedure. 
Table 3

Monetary Policy Surprises Derived from Federal Funds Futures

$$
\text { Policy Surprise }=\frac{D}{D-d} \Delta f u t^{f f},
$$

\begin{tabular}{|c|c|c|c|}
\hline & \multicolumn{2}{|c|}{$\begin{array}{l}\text {---Average Absolute Value--- } \\
\quad \text { (in basis points) }\end{array}$} & \multirow[b]{2}{*}{$\begin{array}{c}\text { Surprise as } \\
\text { Percent of } \\
\text { Change }\end{array}$} \\
\hline & $\begin{array}{c}\text { Change in } \\
\text { Intended } \\
\text { Funds Rate }\end{array}$ & $\begin{array}{l}\text { Policy } \\
\text { Surprise }^{*}\end{array}$ & \\
\hline $1989: 5$ to $1994: 1$ & 27.3 & 16.1 & $58.9 \%$ \\
\hline $1994: 2$ to $2000: 10$ & 32.5 & 7.8 & $24.0 \%$ \\
\hline
\end{tabular}

Policy surprises are calculated from the change in the federal funds futures contract expiring within the month ( $\Delta f u t^{f f}$ ) from the day before the policy change to the day after, adjusted for the timing of the policy action within the month (where $d$ is the day of the month of the policy action, and $D$ is the total number of days in the month). Data are monthly from 1989:5 to 2000:10. 
Table 4

Autoregressive Properties of the Federal Funds Rate

$$
\Delta f f_{t}=\alpha+\beta_{1} \cdot \Delta f f_{t-1}+\beta_{2} \cdot \Delta f f_{t-2}+\beta_{3} \cdot \Delta f f_{t-3}
$$

\begin{tabular}{lcccc}
\hline \multicolumn{5}{c}{ Monthly Observations } \\
\hline & \multicolumn{4}{c}{ Adjusted } \\
& $\Delta f f_{t-1}$ & $\Delta f f_{t-2}$ & $\Delta f f_{t-3}$ & \\
\hline \multirow{2}{*}{$1983: 1$ to $2000: 10$} & 0.378 & 0.080 & 0.001 & 0.16 \\
& $(5.47)$ & $(1.08)$ & $(0.01)$ & \\
$1983: 1$ to $1987: 11$ & 0.374 & -0.005 & -0.135 & 0.09 \\
& $(2.73)$ & $(-0.03)$ & $(-0.99)$ & \\
$1987: 12$ to $2000: 10$ & 0.315 & 0.205 & 0.176 & 0.32 \\
& $(4.21)$ & $(2.62)$ & $(2.41)$ & \\
\hline
\end{tabular}

\section{FOMC Observations}

\begin{tabular}{|c|c|c|c|c|}
\hline & \multicolumn{3}{|c|}{------- Coefficients ------- } & \multirow[t]{2}{*}{$\begin{array}{c}\text { Adjusted } \\
R^{2}\end{array}$} \\
\hline & $\Delta f f_{t-1}$ & $\Delta f f_{t-2}$ & $\Delta f f_{t-3}$ & \\
\hline $1983: 1$ to $2000: 10$ & $\begin{array}{l}0.323 \\
(3.85)\end{array}$ & $\begin{array}{l}0.146 \\
(1.75)\end{array}$ & -- & 0.15 \\
\hline 1983:1 to $1989: 10$ & $\begin{array}{l}0.364 \\
(2.58)\end{array}$ & $\begin{array}{l}-0.010 \\
(-0.07)\end{array}$ & -- & 0.10 \\
\hline $1989: 11$ to $2000: 10$ & $\begin{array}{l}0.242 \\
(2.49)\end{array}$ & $\begin{array}{l}0.421 \\
(4.44)\end{array}$ & -- & 0.31 \\
\hline
\end{tabular}

T-statistics shown in parenthesis. 
Table 5

Predicting Funds Rate Changes:

Autoregressive Component and the Three-month Treasury Bill Component

$$
\text { Spec. A: } \sum_{i=1}^{3} \frac{4-i}{3} \Delta f f_{t+i}=\alpha+\beta_{1} \cdot \Delta f f_{t}+\beta_{2} \cdot \Delta f f_{t-1}+\beta_{3} \cdot \Delta f f_{t-2}
$$

Spec. B: $\sum_{i=1}^{3} \frac{4-i}{3} \Delta f f_{t+i}=\alpha+\beta_{1} \cdot \Delta f f_{t}+\beta_{2} \cdot \Delta f f_{t-1}+\beta_{3} \cdot \Delta f f_{t-2}+\beta_{4} \cdot\left(i_{t}^{3}-f f_{t}\right)$

\begin{tabular}{|c|c|c|c|c|c|}
\hline & \multicolumn{4}{|c|}{--------- Coefficients ---------- } & \multirow{2}{*}{$\begin{array}{c}\text { Adjusted } \\
R^{2}\end{array}$} \\
\hline & $\Delta f f_{t}$ & $\Delta f f_{t-1}$ & $\Delta f f_{t-2}$ & $\left(i_{t}^{3}-f f_{t}\right)$ & \\
\hline \multicolumn{6}{|l|}{$1983: 1$ to $1989: 3$} \\
\hline Spec. A & $\begin{array}{l}0.596 \\
(3.12)\end{array}$ & $\begin{array}{l}-0.026 \\
(-0.16)\end{array}$ & $\begin{array}{l}-0.058 \\
(-0.24)\end{array}$ & -- & 0.099 \\
\hline Spec. B & $\begin{array}{l}0.500 \\
(2.44)\end{array}$ & $\begin{array}{l}-0.004 \\
(-0.02)\end{array}$ & $\begin{array}{l}0.036 \\
(0.15)\end{array}$ & $\begin{array}{l}0.427 \\
(2.80)\end{array}$ & 0.161 \\
\hline Improvement in $R^{2}$ & & & & & 0.062 \\
\hline \multicolumn{6}{|l|}{$1989: 4$ to $1994: 1$} \\
\hline Spec. A & $\begin{array}{l}0.539 \\
(2.22)\end{array}$ & $\begin{array}{l}0.199 \\
(1.64)\end{array}$ & $\begin{array}{l}-0.217 \\
(-1.04)\end{array}$ & -- & 0.120 \\
\hline Spec. B & $\begin{array}{l}0.383 \\
(1.91)\end{array}$ & $\begin{array}{l}0.200 \\
(2.06)\end{array}$ & $\begin{array}{l}-0.086 \\
(-0.62)\end{array}$ & $\begin{array}{l}0.337 \\
(3.40)\end{array}$ & 0.338 \\
\hline Improvement in $R^{2}$ & & & & & 0.218 \\
\hline \multicolumn{6}{|l|}{$1994: 2$ to $2000: 10$} \\
\hline Spec. A & $\begin{array}{l}0.502 \\
(3.93)\end{array}$ & $\begin{array}{l}0.416 \\
(3.22)\end{array}$ & $\begin{array}{l}0.135 \\
(0.82)\end{array}$ & -- & 0.251 \\
\hline Spec. $B$ & $\begin{array}{l}0.151 \\
(1.35)\end{array}$ & $\begin{array}{l}0.152 \\
(1.72)\end{array}$ & $\begin{array}{l}0.017 \\
(0.19)\end{array}$ & $\begin{array}{l}0.618 \\
(9.60)\end{array}$ & 0.741 \\
\hline Improvement in $R^{2}$ & & & & & 0.490 \\
\hline
\end{tabular}

T-statistics shown in parenthesis. 
Table 6

Predicting Funds Rate Changes:

Autoregressive Component and the Futures Rate Component

Spec. A: $\left(f f_{t+i}-f f_{t}\right)=\alpha+\beta_{1} \cdot \Delta f f_{t}+\beta_{2} \cdot \Delta f f_{t-1}+\beta_{3} \cdot \Delta f f_{t-2}$

Spec. B: $\left(f f_{t+i}-f f_{t}\right)=\alpha+\beta_{1} \cdot \Delta f f_{t}+\beta_{2} \cdot \Delta f f_{t-1}+\beta_{3} \cdot \Delta f f_{t-2}+\beta_{4} \cdot\left(f u t_{t+i}-f f_{t}\right)$

\begin{tabular}{|c|c|c|c|}
\hline & \multicolumn{3}{|c|}{-------- Adjusted R Rtatistics ---------- } \\
\hline & $\begin{array}{c}\text { One Month } \\
\text { Ahead }(i=1)\end{array}$ & $\begin{array}{l}\text { Two Months } \\
\text { Ahead }(i=2)\end{array}$ & $\begin{array}{c}\text { Three Months } \\
\text { Ahead }(i=3)\end{array}$ \\
\hline \multicolumn{4}{|l|}{$1989: 5$ to $1994: 1$} \\
\hline Spec. A & .09 & .12 & .10 \\
\hline Spec. $B$ & .33 & .29 & .29 \\
\hline Improvement in $R^{2}$ & .24 & .17 & .19 \\
\hline \multicolumn{4}{|l|}{$1994: 2$ to $2000: 10$} \\
\hline Spec. A & .17 & .24 & .23 \\
\hline Spec. $B$ & .70 & .78 & .77 \\
\hline Improvement in $R^{2}$ & .53 & .54 & .54 \\
\hline
\end{tabular}


Figure 1

Correlations between monthly changes in the federal funds rate and in various market rates
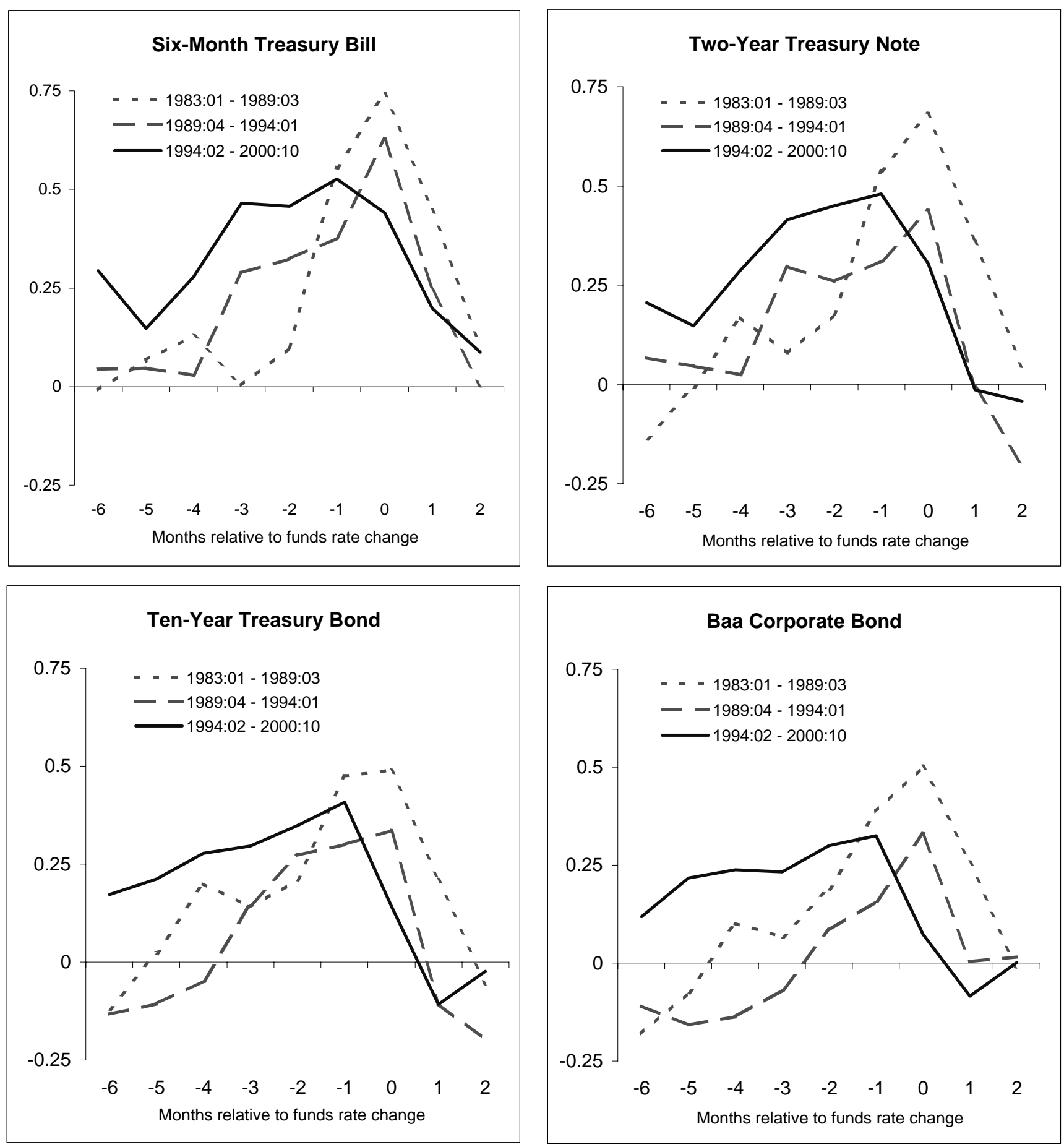

Change in market rate in month indicated relative to a change in the federal funds rate at time zero. For example, a negative number on the horizontal axis is the number of months that market interest rates move in advance of the federal funds rate. 
Figure 2

Significance of lagged changes in various market rates in predicting current changes in the federal funds rate.
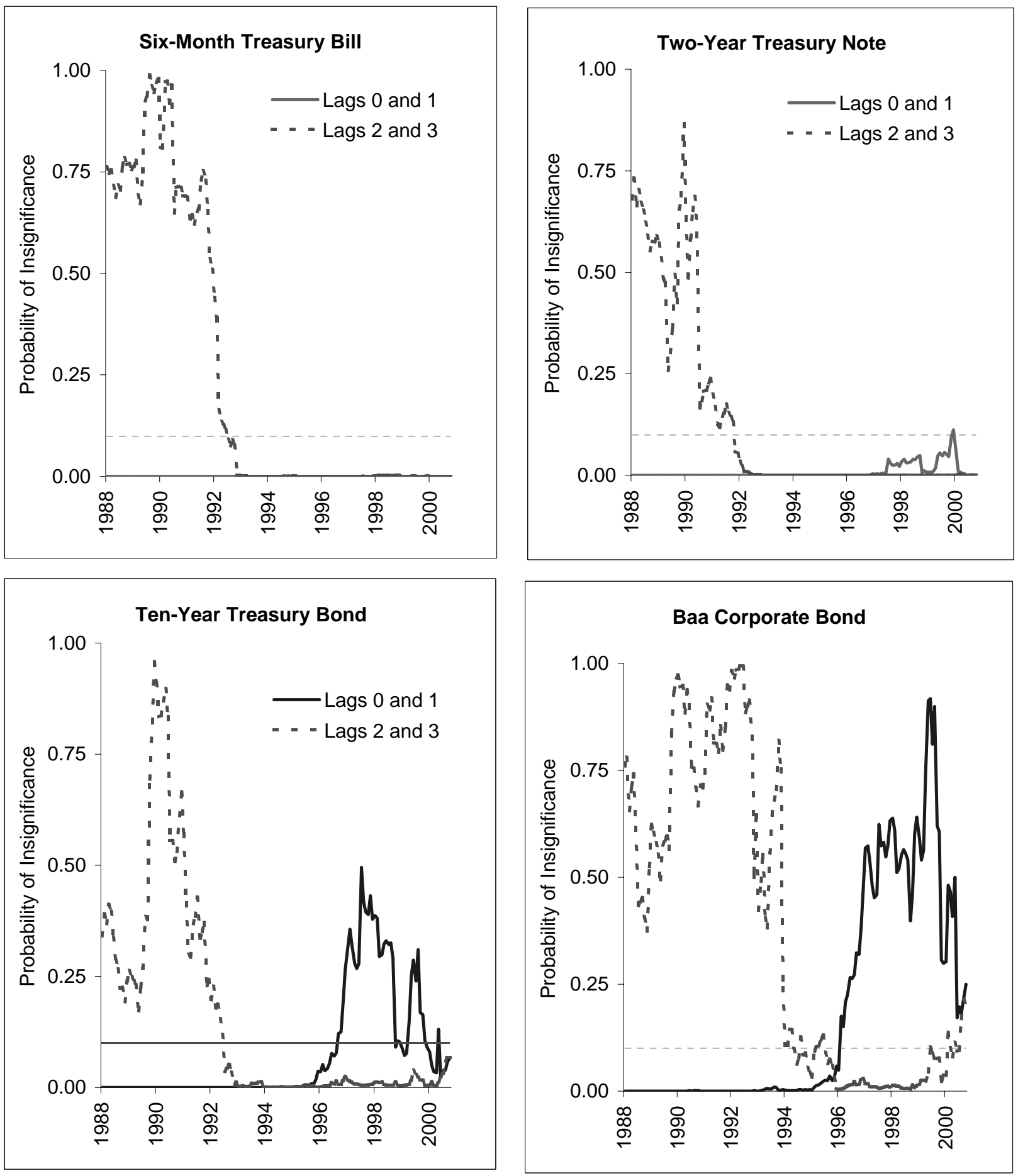

Regressions estimated over a five-year rolling sample, with the horizontal axis indicating the end point of the window. The horizontal line marks the $10 \%$ significance level. 
Figure 3

Improvement in the predictive power of the three-month Treasury bill rate.

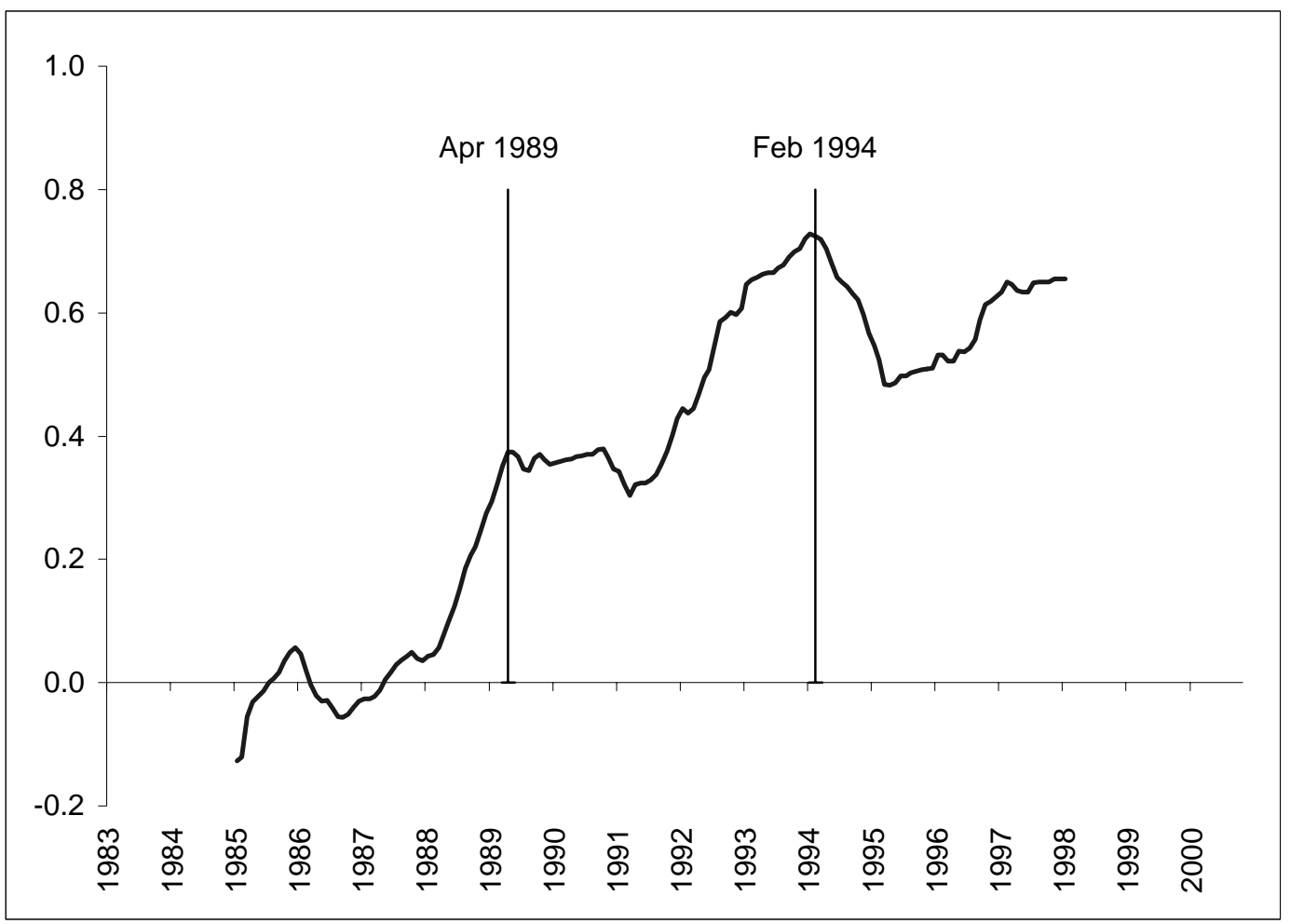

Increase in the adjusted R-squared statistic from the earlier subsample to the later subsample, when the sample is divided at the date indicated. The full sample of monthly data runs from January 1983 through October 2000. 
Figure 4

Likelihood ratio test statistic at each potential breakpoint (Andrews test).

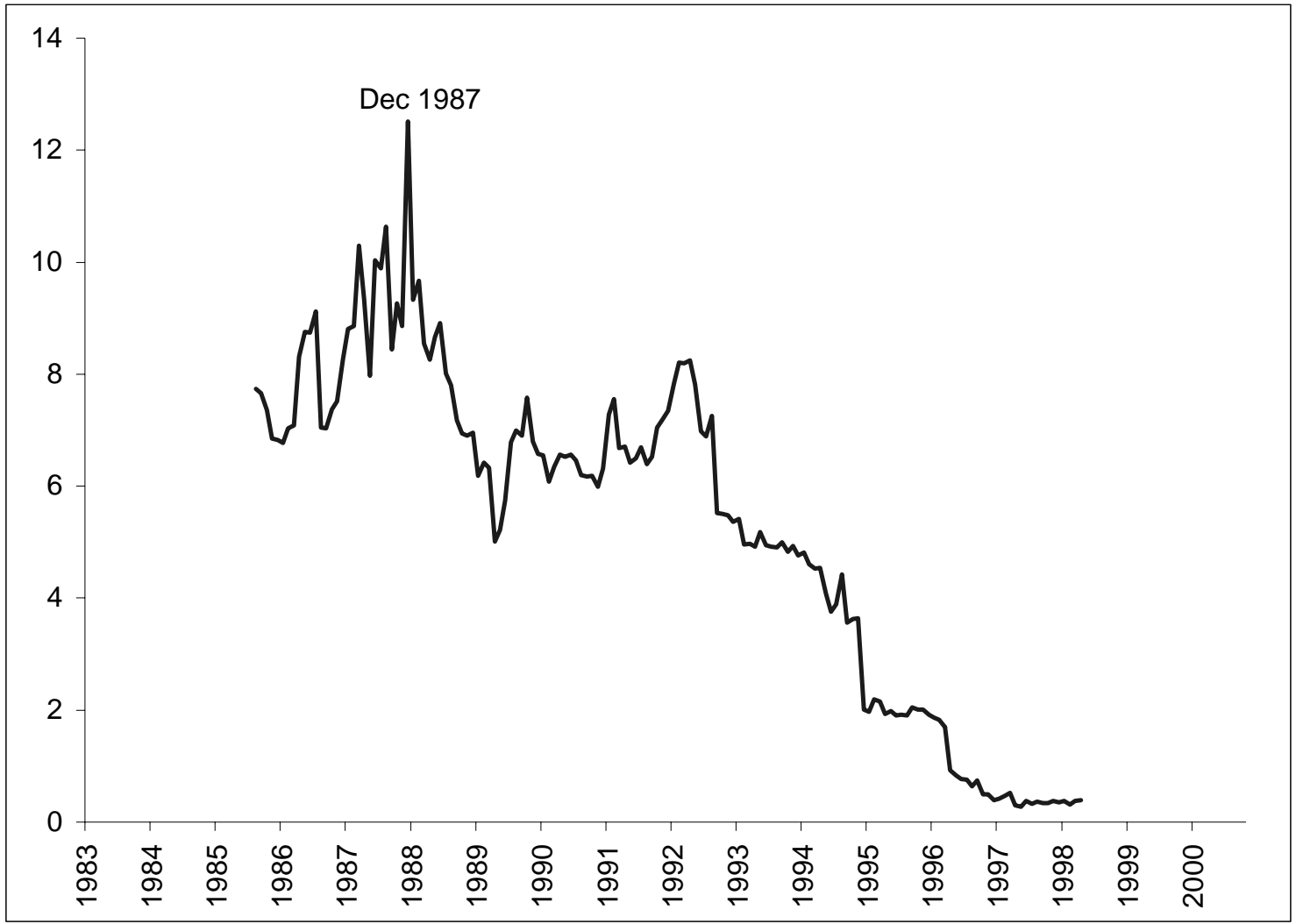


Figure 5

Expected cumulative change in the federal funds rate following a given 25 basis point tightening.

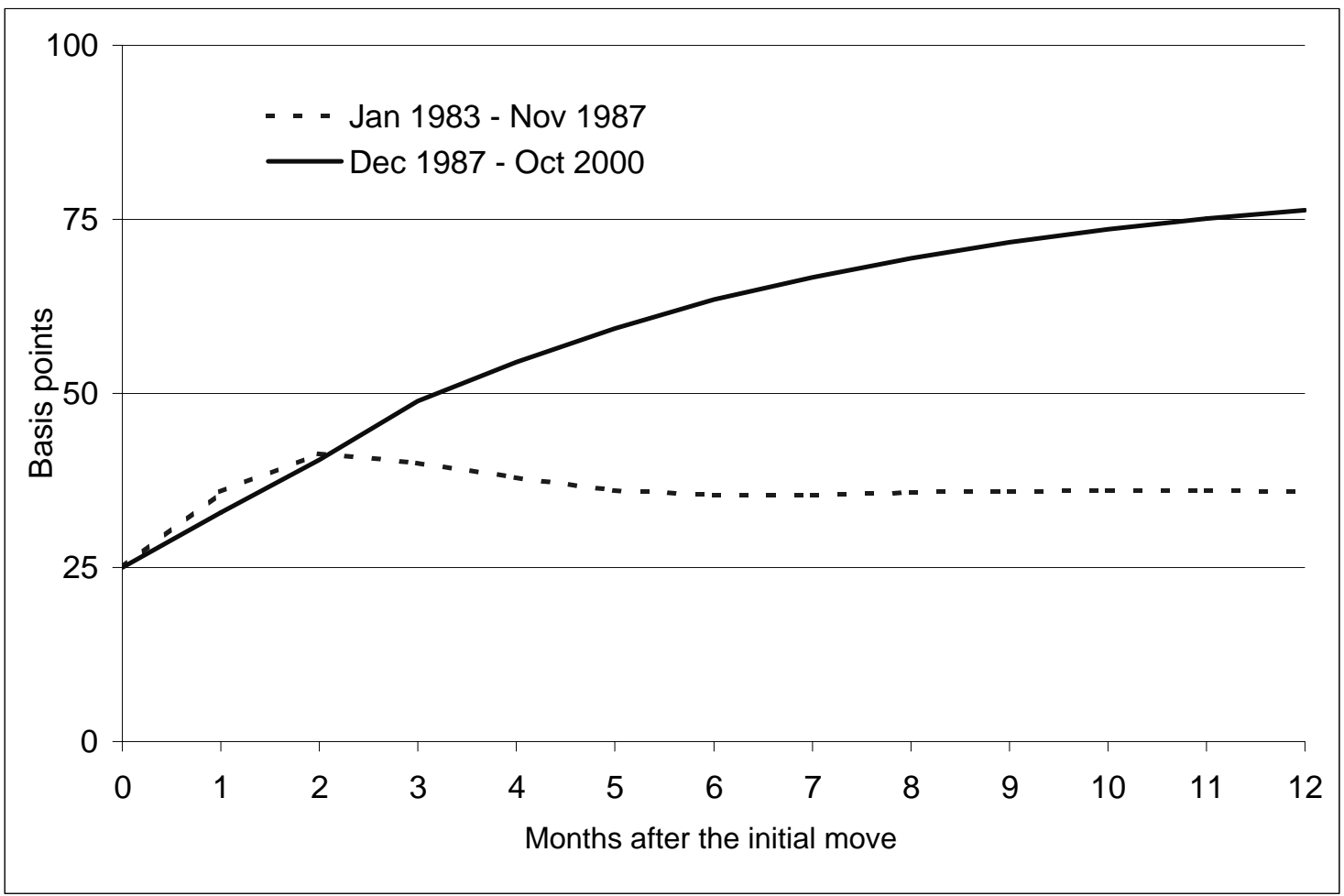

